Vol 2 No 2 Desember 2021

Jurnal AlphaEuclidEdu

Received: 28/09/2021; Resived: 23/11/2021; Accepted: 30/12/2021

\title{
PROSES BERPIKIR SISWA DALAM MEMECAHKAN MASALAH SISTEM PERSAMAAN LINEAR TIGA VARIABEL BERDASARKAN GAYA KOGNITIF DI SMK
}

\author{
Dea Angella, Edy Yusmin, Dian Ahmad \\ Program Studi Pendidikan Matematika, FKIP, Universitas Tanjungpura, Pontianak \\ Email: angelladea44@gmail.com
}

\begin{abstract}
This research aims to thingking process students in cognitive field independent styles in solving mathematical problems in the material three variable linear equation system and to describe the process students in cognitive field dependent styles in solving mathematical problems in thingking material three linear equation. The method used in this research was qualitative descriptive. This research his front used tests, interview and documentation. The test used to determine to cognitive style of each student and the material description of the system of three variable linear equations to determine the thought process. The interview method is used to supplement information. While the docementary is presented in a from that includes photographs during reserach and can be used adevidence that researchers have carried out the research process. The result of thingking of students with cognitive field independent style in solving mathematical problems in material system of linear equations three variable tend to be conceptual, this can be seen from the result of analysis that the subject is able to achieve the indicators of conceptual thingking process, three variable tend to be semiceptual, this can be seen from the result of analysis that most subject are able to achieve the indicators until the completion plan.
\end{abstract}

Keywords : Thinking Process, Cognitive Style, Problem Solving

\section{Pendahuluan}

Penelaahan ilmu hitung berdasarkan PerMenDikBud No. 22 Tahun 2016 sesuai Kurikulum 2013 terdiri dari: (1) menafsirkan rancangan ilmu hitung, menjelaskan implikasi serta menerapakan rancangan secara efektif, patut, teliti, serta cermat dalam menyelesaiakan kesulitan, (2) melakukan demonstrate bawaan dari ilmu hitung, menyalahgunakan ilmu hitung berisi mempersiapkan absreaksi, menentukan alasan, mencari informasi maupun menjelaskan ide serta afirmasi ilmu hitung,(3) mengatasi kesulitan yaitu kepandaian mengatasi kesulitan, menyusun show penyelesaikan ilmu hitung, menyempurnakan demonstrate ilmu hitung, serta menyampaikan pemecahan yang akurat, serta (4) memahami alasan analitis kontruksi bagan, graph, lambang, maupun perangkat lainnya yang mampu memperjelas persoalan maupun bentuknya.

Berdasarkan maksud penelaahan ilmu hitung adalah, mampu meringkas bahwa setelah mengikuti penelaahan ilmu hitung siswa wajib berupaya mengetahui rancangan serta mengaplikasikan rancangan ilmu hitung, melaksanakan penyelewengan ilmu hitung, mengatasi persoalan serta menjabarkan, mengkomunikasikan alasan kedalam kontruksi bagan, graph, representasi, atau perangkat lainnya. Menganalisis ilmu hitung adalah berupa menghitung semata, tetapi murid harus melakukan cara berlogika, berasumsi 
Vol 2 No 2 Desember 2021

Jurnal AlphaEuclidEdu

Received: 28/09/2021; Resived: 23/11/2021; Accepted: 30/12/2021

responsif beserta analitis, mampu mengerjaka kecurangann cabang ilmu hitung, berupaya melakasanakan abstraksi information, mengatasi kesulitan abstraksi cabang ilmu hitung berbeda bersama kesulitan aktivitas intern. Bahwa berasumsi cabang ilmu hitung melambangkan suatu cara berasumsi yang diperoleh murid (Widiyanto et al., 2021).

Berasumsi cabang ilmu hitung menurut Kieran (2004: 149), merupakan cara berasumsi yang melibatkan perkembangan cara berasumsi menggunakan aljabar. Kieran (2004: 141-142) juga menjelaskan bahwa kategori kepandaian berasumsi pada siswa meliputii: (1) kegiatan menggeneralisasi, mengimplikasikan penyusunan aforisme maupun pernyataan serta perbandingan materi ilmu hitung; (2) kegiatan konversi, berasosiasi pada perubahan karkater pernyataan ataupun perbandingan yang berbasis hukum; dan (3) kegiatan kooperatif mengimplikasikan aljabar seperti satu instrument bermanfaat internal menyelesaiakan komplikasi aljabar maupun komplikasi lain.

Berdasarkan hasil tes matematika pada kelas X mengenai materi persaamaan linear tiga variabel, diperoleh data bahwa hanya $72,00 \%$ siswa yang termasuk field dependent dan $27,00 \%$ siswa termasuk field independent dari 32 siswa yang mempunyai kategori tersebut. Dari hasil interview kepada beberapa guru yang berada di sekolah yang membimbing matematika kelas X di SMK Negeri 7 Pontianak pada tanggal 30 Maret 2021, murid invalid menafsirkan model pemecahan persoalan pada pelajaran sistem persamaan linear tiga variabel. Beberapa murid mengalaami kesulitan adalah kesulitan siswa dalam menentukan segala sesuatu yang diketahui dari persoalan dan segala sesuat yang ditanyakan dalam persoalan apa yang diketahui dari nilai yang diketahui pada elastis yang diperoleh atas satu perbandingan, beserta komplikasi analitis mengajukan perkara kontruksi pertanyaan fiksi, dan kesukaran analaitis mengerjakan aktivitas analitis menyempurnakan perbandingan ilmu hitung serupa atas multiplikasi desimal (Panjaitan et al., 2021); (Sulistyowati, 2021).

Apabila berkaitan melalui kepandaian berasumsi cabang ilmu hitung, mengindikassikan kepandaian berasumsi ilmu hitung murid masih kecil, karena masih belum memenuhi indikator berasumsi ilmu hitung. Kepandaian dalam berasumsi didapatkan kepada penelaahan ilmu hitung atas seluruh pelajaran analitis mengatasi kesulitan efektif kesulitan ilmu hitung maupun diluar ilmu hitung yang wajib dikerjakan memerlukan persepsi ilmu hitung, kapabilitas kemahiran berasumsi cabang ilmu hitung sangat penting untuk dikuasai oleh murid (Armiyansyah et al., 2021).

Kepandaian cara berasumsi murid dalam menyelesaikan kesulitan ilmu hitung sesuai dijelaskan kepada pengajar, bahwa pengajar lebih tertarik untuk melaksanakan penelitian tentang kepandaian cara berasumsi siswa dalam mengatasi kesulitan berdasarkan gaya kognitif soal atas pelaajran persamaan linear tiga variabel pada siswa kelas X SMK Negeri 7 Pontianak. Tujuan dari penelitian ini untuk mengetahui kepandaian berasumsi murid dalam mengatasi persoalan yang berasosisasi dengan pengajaran persamaan linear tiga variabel. 
Vol 2 No 2 Desember 2021

Jurnal AlphaEuclidEdu

Received: 28/09/2021; Resived: 23/11/2021; Accepted: 30/12/2021

\section{Metode Penelitian}

Prosedur yang digunakan analitis penelitian ini ialah prosedur deskriptif kualitatif karena pada penelitian ini ialah akan mendeskripsikan kapasitas berasumsi murid beranalitis menyelesaikan persoalan ilmu berdasarkan gaya kognitif analitis mengendalikan komplikasi murid.

Pokok kalimat antobjek penelitian sebanyak empat murid kelas X di SMK Negeri 7 Pontianak yang mempunyai gaya kognitif berbeda- beda, dua orang siswa mempunyai gaya kogintif independent dan dua orang siswa mempunya gaya kognitif dependent, setiap murid mempunyai kemampuannya dalam dirinya.. Pemilihan siswa dilihat dari kemampuan siswa dalam mengatasi kesulitan matematis dari tes geft dan wawancara.

Berikut ini jadwal kegiatan perizinan uji coba, uji coba dan pelaksanaan penelitian tertera pada tabel di bawah ini:

Tabel 1. Jadwal Kegiatan

\begin{tabular}{|c|c|c|c|}
\hline No. & Hari/Tanggal & Kegiatan & Tempat \\
\hline 1 & Kamis, 4 Maret 2021 & $\begin{array}{c}\text { Perizinan Uji Coba } \\
\text { Soal dan Penelitian }\end{array}$ & $\begin{array}{c}\text { SMK Negeri 7 } \\
\text { Pontianak }\end{array}$ \\
\hline 2 & Selasa, 9 Maret 2021 & $\begin{array}{c}\text { Pelaksanaan Uji Coba } \\
\text { Soal }\end{array}$ & $\begin{array}{c}\text { SMK Negeri 7 } \\
\text { Pontianak }\end{array}$ \\
\hline 3 & Jumat, 12 Maret 2021 & Pelaksanaan & SMK Negeri 7 \\
& & Penelitian & Pontianak \\
\hline
\end{tabular}

Metode pengambilan data analitis observasi adalah tes dan non tes (wawancara). Instrumen pengambilan data adalah pertanyaan eksperimen keahlian berasumsi ilmu hitung beserta eksemplar konsultasi. Eksperimen kapasitas berasumsi ilmu hitung terdiri dari empat soal berbentuk esai yang disusun berdasarkan indeks berasumsi ilmu hitung.

\section{Hasil dan Pembahasan}

Hasil

Hasil yang didapatkan oleh penelitian ialah hasil tes kemampuan berpikir geft dalam menyelesaikan soal materi persamaan linear tiga variabel pada empat siswa SMK Negeri 7 Pontianak. Pemberian tes keampuan berpikir geft berupa dua soal pada hari Jum'at, 12 Marer 2021 dengan durasi pengerjaan 40 menit.

Tabel 1. Data Hasil Jawaban Siswa pada Group Embedded Figures Test (GEFT) di Kelas X SMK Negeri 7 Pontianak.

\begin{tabular}{|c|c|}
\hline Jumlah Siswa & Jenis Gaya Kognitif \\
\hline 2 & FD \\
\hline 2 & F1 \\
\hline
\end{tabular}


Vol 2 No 2 Desember 2021

Jurnal AlphaEuclidEdu

Received: 28/09/2021; Resived: 23/11/2021; Accepted: 30/12/2021

Berdasarkan Tabel 1, terlihat bahwa dari enam siswa kelas $\mathrm{X}$ yang mampu menjawab sesuai dengan indikator kemampuan field independent dan field dependent dua siswa, siswa yang menjawab field dependent siswa membutuhkan bantuan guru atau teman sekelas, siswa yang menjawab denga field independent, siswa menyelesaiakn persoalannya sendiri tanpa bantuan teman sekelasnya.

\section{Pembahasan}

Cara belajar mengajar menitik beratkan pada upaya agar materi yang diberikan dapaat dipahami siswa dalam pemebelajaran yang dilakukan oleh guru dengan lebih mudah dapat dipahami oleh siswa yang selanjutnya dapat diterapkan dalam memecahkan persoalan baik yang dirumuskan secara berkelompok maupun persoalan dalam diri sendiri. Demikian, tujuan utama dalam pembelajaran ilmu hitung yaitu kelogisan berasumsi, pendirian tingkah laku murid serta kapasitas analitis implementasi ilmu hitung. Untuk itu, seorang guru harus merancang kegiatan pembelajaran dengan tepat dan mampu memfasilitasi kegiatan belajar siswa di kelas.

Dalam melaksanakan kegiatan di kelas, akan lebih baik jika seorang guru mengetahui cara berpikir dari siswanya. Dengan memahami metode berasumsi murid, guru menerima, melihat kelelahan murid dan mampu mendiskusikan persoalan yang sesuai dengan proses berasumsinya. Selain itu, guru sebaiknya juga mengetahui karkteristik siswanya, salah satunya yaitu perbedaan gaya kognitif murid yang akan mempengaruhi cara penerimaan dan pengolahan informasi yang akan diperoleh.

Dalam penelitian ini, gaya kognitif murid X TBSM dibedakan menjadi dua, yaitu field independent dan field dependent. Murid dengan gaya kognitif field independent cendrung lebih mandiri dalam menyelesaikan persoalan, sedangkan murid dengan gaya field dependent cendrung membutuhkan bantuan dalam menyelesaikan persoalan. Dari tiga puluh dua siswa yang mengikuti tes gaya kognitif terdapat data sebanyak empat murid mempunyai gaya kognitif field independent dan dua puluh dua murid memiliki gaya kognitif field dependent. Dari kuantitas tersebut, peneliti mengambil masing-masing empat murid, penelitian untuk mengetahui cara berasumsi dari masing - masing siswa dalam menyelesaiakan persoalan sistem persamaan linear tiga variabel. Langkah-langkah menyelesaiakan persoalan menurut Polya meliputi memahami masalah, merencanakan penyelesaian, dan mengevaluasi hasil. Adapun metode berasumsi siswa dalam peneltian ini dibedakan menjadi tiga yaitu, abstrak,semikonseptual, dan kamputasional. cara berasumsi abstrak yaitu cara berasumsir yang selalu mengatasi masalah dengan menggunakan langkah yang telah dimiliki berdasarkan hasil pelajarannya. cara bersumsi semikonseptual yaitu cara berasumsi yang cenderung menyelesaiakan suatu soal dengan menggunakan langkah tetapi karena pemahamannya terhadap materi tersebut masih kurang maka penyelesaiannya dicampur dengan menggunakan intuisi. Sedangkan cara berasumsi komputasional yaitu cara berpikir yang pada umumnya menyelesaiakan suatu soal tidak menggunakan langkah tetapi lebih mengandalkan intuisi. 
Vol 2 No 2 Desember 2021

Jurnal AlphaEuclidEdu

Received: 28/09/2021; Resived: 23/11/2021; Accepted: 30/12/2021

\section{Simpulan dan Saran}

\section{Simpulan}

Berdasarkan hasil analisis data, wawancara serta pembahasannya maka dapat disimpulkan secara umum bahwa metode berasumsi siswa analitis menyelesaikan persoalan ilmu hitung berdasarkan gaya kognitif. Adapun kesimpulan yang diperoleh dalam penelitian yang berjudul “ Proses Berpikir Siswa Dalam Memecahkan Masalah Matematika Materi Persamaan Linear Tiga Variabel Berdasarkan Gaya Kognitif di SMK Negeri 7 Pontianak" adalah sebagai berikut: 1) Cara berasumsi murid gaya kognitif field independent, menyelesaiakan persoalan ilmu hitung analitis pelajaran persamaan linear tiga variabel cenderung konseptual, yang dimaksud konseptual ini adalah siswa mampu memahami indikator cara berasumsi konseptualal ini dapat dilihat dari hasil analisis bahwa siswa mampu memenuhi indikator cara berasumsi konseptual. Siswa dengan gaya kognitif field independent memenuhi indikator mampu menyatakan dengan kalimat sendiri apa yang diketahui dan ditanyakan dalam soal atau mengubahnya dalam kalimat ilmu hitung, mampu membuat rencana penyelesaian dengan lengkap, mampu menyatakan langkah-langkah yang ditempuh dalam menyelesaikan soal menggunakan konsep yang telah dipelajari, dn mampu memeriksa kembali kebenaran atau mengoreksi kesalahan dari setiap langkah penyelesaian sehingga diperoleh hasil yang benar; 2) Cara berasumsi murid dengan gaya kognitif field dependent dalam mengerjaka persoalan ilmu hitung pada pelajaran persamaan linear tiga variabel cenderung semikonseptual, hal ini dapat dilihat dari hasil analisis bahwa sebagian besar murid memenuhi indeks cara berasumsi semikonseptual. Murid dengan gaya kognitif field dependent kurang mampu menyatakan dengan kalimat sendiri apa yang diketahui dan ditanyakan dalam soal atau mengubahnya dalam kalimat matematika, mampu membuat rencana penyelesaian namun tidak lengkap, kurang mampu menyatakan langkah-langkah yang ditempuh dalam menyelesaikan ssoal menggunakan konsep yang telah dipelajari, dan kurang mampu memeriksa kembali hasil kerjaannya supaya ada yang benar atau mengoreksi kesalahan dari setiap langkah pengerjaan sehingga diperoleh hasil yang benar.

\section{Saran}

Berdasarkan hasil temuan dalam penelitian ini, saran yang dapat peneliti sampaikan ialah: 1) Guru dapat menggunakan gaya kognitif sebagai patokan dalam membuat alat evaluasi. Dengan memperhatikan proses berpikir siswa berdasarkan gaya kognitif pada tes group embedded firgures test yang berbeda, pendidik dapat memberikan bantuan atau scaffholding yang tepat untuk meningkat respon siswa ke level yang lebih tinggi; 2) Guru bakal lebih sering memberikan siswa pemahaman, bimbingan dan latihan dalam menyelesaikan persoalan cerita agar murid terbiasa memahami persoalan cerita, merancang model matematika dari soal dan merencanakan penyelesaian serta memperoleh solusi yang diharapkan; 3) Guru harus memilih strategi yang membuat siswa tidak sekedar menghapal rumus tetapi juga memahaminya. Untuk penelitian selanjutnya, 
Vol 2 No 2 Desember 2021

Jurnal AlphaEuclidEdu

Received: 28/09/2021; Resived: 23/11/2021; Accepted: 30/12/2021

diharapkan memperhatikan instrumen soal agar lebih baik lagi serta menyempurnakan kekurangan pada penelitian ini.

\section{Referensi}

Ameron, Barbara Ann Van. (2002). Reinvention Of Early Algebra. Tesis. Universiteit Utrech, Nederlands.

Driscoll, M. 1999. Fostering Algebraic Thinking: A Guide for Teachers Grade 610.Portsmouth, NH, Heinemann. Tersedia di www.thetrc.org/trc/download/.../fosteringalg.pdf, [diakses tanggal 5 Juni 2020].

Julie, Ellis. (2004). What's Your Angle, Phytagoras?. (Online). (diakses tanggal 1 Agustus 2020).

Kriegler, S. (2011). "Just What is Algebraic Thingking?. Submitted for Algebraic Concepts in the Middle School."

Kieran, Carolyn. (2004). Algebraic Thinking in the Early Grades: What Is It? The Mathematics Educator. Vol. 8. No. 1.

NCERT, 1961. Algebraic Expressions and Identities. Government of India.

NCTM, 2000. Principles and Standars for School Mathematics. United States of America: The NCTM, Inc.

Armiyansyah, Sugiatno, \& Bistari. (2021). Hambatan siswa dalam belajar matematika dikaji dari kepercayaan matematis 1 1,2,3. Jurnal AlphaEuclidEdu, 2(1), 40-50.

Panjaitan, S., Hartoyo, A., \& Fitriawan, D. (2021). Eksplorasi Etnomatematika Kain Tenun Songket Suku Melayu Sambas. Jurnal AlphaEuclidEdu, 2(1), 19-31. https://jurnal.untan.ac.id/index.php/AlphaEuclidEdu/article/view/47890

Sulistyowati, E. (2021). Pengaruh Penggunaan Model Pembelajaran Kooperatif Tipe Inside Outside Circle ( Ioc ). Jurnal AlphaEuclidEdu, 2(1), 32-40.

Widiyanto, A., Hartoyo, A., \& Nursangaji, A. (2021). Kemampuan berpikir kreatif siswa berdasarkan adversity quotient pada materi dimensi dua 1. Jurnal AlphaEuclidEdu, 2(1), 64-73.

Sudjana, Nana, dan Ibrahim, 1989, Penelitian Kualitatif dan Kuantitatif. Jakarta: Rineka Cipta.

Sukmawati, Ati (2015). Berpikir Aljabar dalam Menyelesaikan Masalah Matematika. Jakarta: Rineka Cipta. 